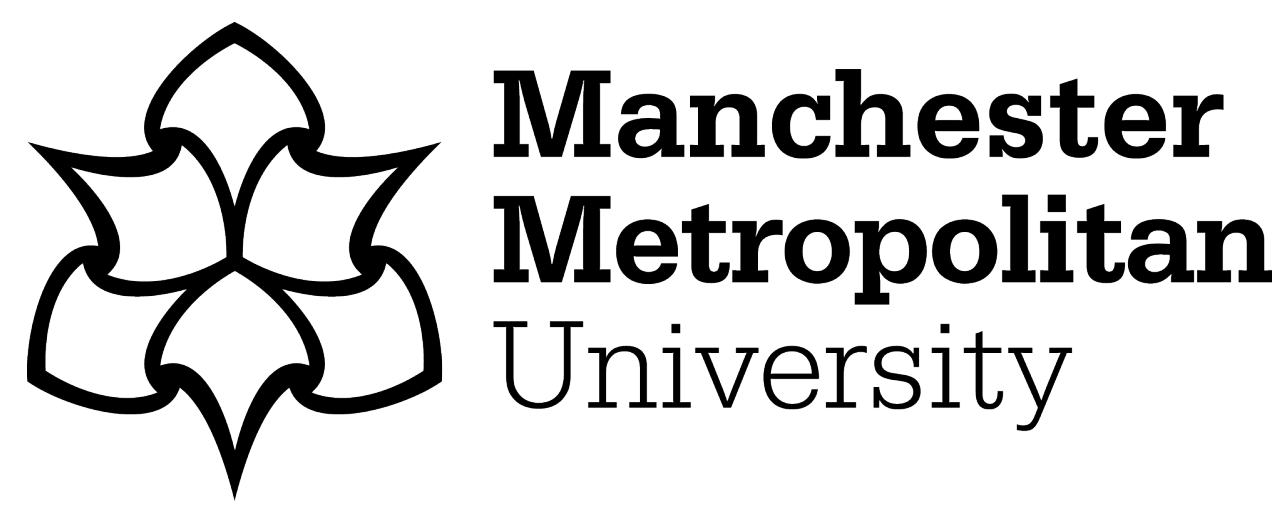

Skains, R Lyle (2020) Discourse or gimmick? Digital marginalia in online scholarship. Convergence: The International Journal of Research into New Media Technologies, 26 (4). pp. 942-955. ISSN 1354-8565

Downloaded from: https://e-space.mmu.ac.uk/625714/

Version: Accepted Version

Publisher: SAGE Publications

DOI: https://doi.org/10.1177/1354856519831988

Please cite the published version 


\title{
Discourse or gimmick? Digital marginalia in online scholarship
}

Skains, R.L., 2019. Discourse or Gimmick? Digital Marginalia in Online Scholarship. Convergence. doi: 10.1177/1354856519831988.

\begin{abstract}
Marginalia has been studied as discourse, as historical documentation, and as evidence of reader response. As many academic texts are now available electronically, it seems a natural step to incorporate the interactive, social functions of the Web 2.0. Digital marginalia in an academic publishing context has been a largely unsuccessful venture to this date, yet there are several promising developments. Tools have emerged that enable readers annotate online texts in an approximation of paper-based marginalia, with the additional affordances of two- (or many-) way discourse, digital archiving, and the ability to hide the annotations. This paper reviews the contemporary practices of digital marginalia, narrowing in to focus on digital marginalia as a form of academic discourse and peer review. I analyze several case studies of digital marginalia and discourse within this context, including Nature's trial of open peer review, Wellcome Open Research, PLOS ONE and PubPeer's systems, as well as my own experience using open peer review with Hypothes.is in a special "disrupted" issue of the Journal of Media Practice. The paper examines the relative success of these initiatives, attitudes toward open peer review, and concludes with some promising developments for the future of digital marginalia and discourse in academic publishing.
\end{abstract}

Keywords

Marginalia, digital discourse, Web 2.0, open peer review, online publishing

\section{Introduction}

Writing in other people's texts is a centuries-old habit, from monkish scribblings on manuscripts to student notes in library books. Marginalia has been studied as discourse, as historical documentation, and as evidence of reader response (Jackson, 2001). Recent studies on digital annotation have labeled it "digital social reading" (Blyth, 2014), as readers can share their annotations and read others'; some authors are experimenting with this function in creative texts. As many academic texts are now available electronically, from online journals to e-books, it seems a natural step to incorporate the 
interactive functions of the Web 2.0 - comments, annotations, shares, likes - into a digital discourse occurring on a source text itself. The benefits of such a free and open academic discourse are numerable, yet uptake of these technologies for academic discourse has been slow, despite several high-profile trials. Digital marginalia in an academic publishing context has been a largely unsuccessful venture to this date, yet there are several promising developments that indicate these early failures may merely be growing pains.

From the origins of print culture, manuscripts and books have offered a concrete, physical location for discourse to occur. This discourse is, of course, in the "official" published text, but it is also present in margin notes, editorial comments, dedications, doodles, annotations, highlighting, and other actions that occur on the physical pages. "In the Middle Ages, it [marginalia] was a legitimate and desirable way for scholars to comment on the subject, thus interacting with the text and (therefore) with other readers as well" (Fajkovic and Björneborn, 2014: 902). The text prior to the era of printing was typically a shared copy, and its margins afforded an extension of oral discourse in this newly fixed and semi-permanent form. H.J. Jackson notes that as the book became a mass-produced item of property (with a tipping point identified as 1820), that mimicry of oral discourse became more of a private conversation between reader, text, and author (Jackson, 2001). In his study of book marginalia, Stephen Orgel notes that "[T] he book is not simply a text; it is a place and a property" (2015: 5); books and the printed page afford space and opportunity for readers to express their thoughts and reactions to the printed text, as closely as possible to that printed text. John Unsworth identifies annotations as "scholarly primitives": one of the basic functions 
common to scholarly activity across disciplines, over time, and independent of theoretical orientation (2000: n.p.).

Digital spaces have also emerged that afford discourse, within the context of the Web 2.0's features of commenting, sharing, and re-mixing content (O'Reilly, 2007). The "social web" is an actualization of Walter Ong's notion of secondary oral culture (Ong, 1982), as the perceived spontaneity and evanescence of digital social media afford utterances of a more "natural" or oral nature, while the software platforms preserve and distribute them (usually permanently) in a digital version of print publication. Most of this digital discourse currently comes in the form of comments on articles and blogs, in sharing of texts on social media sites like Facebook and Twitter, and in ensuing comments and discussions on those social media sites. In contrast to book marginalia, this discourse is largely occurring outside the physical/virtual space of the text, rendering it distanced from the text and not wholly categorizable as marginalia.

In the past couple of years, several tools have emerged that enable readers on the web to annotate the text directly, regardless of the site's incorporated Web 2.0 features. Genius, Scrible, Notable, Diigo, ReadSocial, and Hypothes.is are just a few of the programs and browser extensions that enable readers on the web to highlight, annotate, share, and discuss web texts, both publicly and privately. These tools introduce a paper-mimicking affordance to the spaces of the web, enabling readers to mark up and annotate online texts in an approximation of paper-based marginalia, with the additional affordances of two- (or many-) way discourse, digital archiving, and the ability to hide the annotations.

As more academic texts move to online spaces for both economical and 
distribution purposes, there is a need to make these digital spaces more amenable to the practices of reviewing and discussing scholarly texts. More scholarship is being published now than ever before, and the "classical" system of peer review cannot keep up, causing delays and errors (Walker and Rocha da Silva, 2015). Further, there is some evidence that digital publication, distribution, and peer-to-peer discourse may enable a wider diversity in that discourse and greater participation by marginalized voices, in an extension of social media's ability to lower barriers to participation (ibid.; Faulkes, 2014). Zen Faulkes also notes that post-publication review and discourse may result in greater attention to the text and therefore more citations and influence for the contributing authors (2014).

The following sections of this paper review the practices of marginalia in contemporary usage, narrowing in to focus on digital marginalia as a form of academic discourse and peer review. I analyze several case studies of digital marginalia and discourse within this context, including Nature's trial of open peer review, Wellcome Open Research, PLOS ONE and PubPeer's systems, as well as my own experience using open peer review with Hypothes.is in a special "disrupted" issue of the Journal of Media Practice. The paper examines the relative success of these initiatives, attitudes toward open peer review, and concludes with some promising developments for the future of digital marginalia and discourse in academic publishing.

\section{Contemporary Marginalia in Action}

As noted above, marginalia has existed as long as the page. Early printed books mimicked manuscripts in physical form, leaving room for annotations in margins and 
between lines; similarly, early readers and printers took on the practices afforded by the form, continuing the practice of including annotations in the spaces afforded (Jackson, 2001: 45-46). For the purposes of this paper, I will focus primarily upon marginalia as it is used in contemporary print culture, as that is the practice that digital interfaces attempt to emulate in their virtual environments. These marginalia come in the form of editorial notes, reader commentary, and peer review, which have all developed through their use in print publications.

Editorial notes include marks and feedback from editors on authors' drafts as well as the authors' own notes, whether to the editors or to themselves, as H.J. Jackson and Stephen Orgel cover extensively $(2001 ; 2015)$. In terms of post-publication marginalia, however, most of these annotations are confined to footnotes. "The footnote made a visual statement about the relative importance of the author and the editor or interpreter by firmly demoting commentary to the bottom of the page and a smaller typeface" (Jackson, 2001: 56); the purpose of footnotes (and perhaps moreso, endnotes) is to offer the reader a chance to synthesize the text on their own terms, choosing whether or not to include the editorial discourse presented below. Footnotes and endnotes are primarily communications by the author(s), but in later reprints and annotated editions may contain additional discourse from editors. ${ }^{1}$

The more familiar notion of marginalia comes in the form of highlights and notes as readers traverse the text and engage in in-text discourse with it, themselves, their future selves, the implied author (Booth, 1961), and any future reader of the text. These annotations are a paradoxical fixture in print culture: they are recognized by some as beneficial to the reader, as scholars and teachers throughout history have taught 
students to annotate their readings as a method of learning (Fajkovic and Björneborn, 2014; Jackson, 2001; Macfadyen, 2011; Marshall and Brush, 2004; Orgel, 2015); they are also viewed as culturally taboo, as destructive and defacing, particularly in shared texts such as library books (Fajkovic and Björneborn, 2014; Jackson, 2001; Orgel, 2015). Annotators themselves recognize this taboo even as they scribble in shared texts, sometimes restricting themselves to pencil marks, but nonetheless incorporating their own additions out of a need to interact with the text, whether for learning or for commentary (or both) (Fajkovic and Björneborn, 2014). Unlike editorial notes, however, most post-publication marginalia is not intended as communication, and their meanings are often fleeting: "personal annotations suffer crises of intelligibility: they often do not retain their meaning over time and beyond short-term tasks, even to their authors" (Marshall \& Brush 2004, 350). Some can, of course, serve as rich fodder for historians or biographers, as Jackson notes (2001), but most are labeled defacement. ${ }^{2}$ Academic discourse in the form of annotation and marginalia overlaps both editorial annotation and reader commentary, in the form of peer review. In the classical model (Walker and Rocha da Silva, 2015), peer review occurs on the pre-publication text, typically in the form of general comments (some of which may indicate particular points in the text). As more journals become more digitizedexist within the digital environment and scholars become more familiar with digital editing tools, some aspects of peer review and editing take place as tracked changes in Microsoft Word documents and/or edits on PDF documents.

Several publications in recent years have made attempts to modify this system, in light of current Web 2.0 technologies, fashioning new models of online peer review. 
These include "peer-to-peer (p2p)" review, in which the text is open to a select group of peers to engage in open discourse amongst themselves regarding its potential revisions (e.g., Electronic Book Review, n.d.); crowd-sourced peer review (e.g., MediaCommons Press, n.d.; Palgrave Macmillan, 2013); post-publication open peer review, in which all aspects of submitting, reviewing, revising, and publishing are made public (e.g., Wellcome Trust, n.d.); and "online journal clubs" offering post-publication discourse on specific articles (e.g., PubMed Commons, n.d., PubPeer, n.d.). The annotations in these instances is are distinguished from reader commentary annotations in books in that they are intended for communication, whether of content criticism or editorial revisions. Thus the annotators are "far more self-conscious in their work" (Jackson, 2001: 7), and the annotations are purposeful communications for specific audiences.

As more reading, both for entertainment and scholarly purposes, moves to digital spaces, there is a more pressing need for digital annotation across the range of users and uses. For e-books read on e-reader devices or apps, annotation is enabled by software functions mimicking older forms of marking up texts (as it seems all new technology must): highlighting and text-input annotations, saved to the reader's user account (e.g., Amazon Kindle Highlights and Notes). A reader may annotate a downloaded library book, but their annotations disappear with the loan period, never attaining their potential as a forward-propelled discourse (Fajkovic and Björneborn, 2014: 914). Likewise, while "popular highlights" can be viewed in the reader's own ebook, there is not yet a universal system for sharing in-text notes (though they can be shared through social media outside the text) (Amazon.com, n.d.). A number of digital annotation tools for online reading, however, have emerged: Annotate.co, Genius Web 
Annotator, ReadSocial, and Hypothes.is. These tools incorporate bookmarking and overlay functions: imagine that each page of a book could be overlaid with a transparent sheet, where the reader could mark up the text at will without defacing the original page. In addition, the reader has the option to toggle the annotations on or off, to tag them so that they are included in specific conversations, to share the annotations publicly or keep them private, to contribute anonymously or not, and to converse (potentially in real-time) with other readers on the same text.

The benefits of these tools, and of digital annotation in general, are many. As noted above, as more work is published in a higher education economy where staff are increasingly overworked, the classical system of peer review becomes slower and slower; models that speed up this process are desirable. Digital environments that include commenting functions and annotation overlays afford ongoing academic discourse, debate, and peer review, something that was relegated to follow-up articles and letters to editors in print publishing (Davies and Delamothe, 2005). These debates can occur in near real-time, a particular benefit to cutting edge topics such as stem cell research, political debates, and controversial issues (Knoepfler, 2015: 222). The discourse is opened to secondary audiences, including end-users of research (doctors, patients, engineers, artists, etc.) as well as marginalized populations that might not have extensive access to all publications in which academic discourse plays out (Davies and Delamothe, 2005; Faulkes, 2014). Further, open reviews and discourse give researchers "much needed qualitative evidence for their promotion and tenure narratives" (Odell and Pollock, 2016: n.p.).

So the question remains: why do the majority of academic publishers still 
employ the classical methods of peer review and discourse, when these digital tools are available, beneficial, and (by and large) free for all to use? To answer that question, I examine several examples in the next section, focussing on Nature's open peer review trial and my own experience publishing an article through open peer review with a special issue of the Journal of Media Practice.

\section{Open Peer Review}

Open peer review includes various styles, including anonymized peer review, comments that are later made public, on-text annotations, and/or post-textual comments. While open peer review is a model that does not lend itself to any particular research domain, it has primarily been used in the sciences; perhaps this is due to the sheer numbers of publications, or perhaps it is due to the more consistent structures of scientific papers (emphasizing tests and results, rather than analysis and discourse as much of the humanities emphasizes). Speculation aside, scientific publications provide the most well-known and well-studied examples. I will look first at Nature's open peer review trial, then offer insight drawn from my authorial experience of open peer review in The "Disrupted" Journal of Media Practice on the humanities side. Finally, this section concludes with a brief look at other relevant examples, including PubMed Commons, MediaCommons Press, and PubPeer.

\section{Nature's Trial}

The renowned science journal Nature trialled open peer review in 2006 in an attempt to gauge authors' and readers' reactions, as well as test potential innovations to their long- 
running peer review system. All papers submitted to the journal $(1,369)$ during the trial period (1 June to 30 September 2006) that passed an initial editorial assessment (part of the standard practice) were eligible for open peer review. This open peer review consisted of online publication and open review through digital marginalia in the form of signed comments, which were moderated for legal issues and inappropriate language. The papers were simultaneously routed through the journal's traditional closed peer review system.

Of the 1,369 papers during this period that passed the initial editorial assessment, only $5 \%$ of authors agreed to open peer review. Despite healthy online traffic ("5,600 html page views per week and about the same for RSS feeds" [Nature Editors, 2006: n.p.]), these 71 papers received a total of 92 comments, which were heavily concentrated on only 8 papers; 33 papers (46\%) received no comments at all, despite the editors' best efforts to garner them. The editors reported that "it was like 'pulling teeth' to obtain any comments", that "generally the comments were judged to be more valuable editorially than technically", and that no comment influenced editors on publication decisions (ibid.). As a result, and despite high levels of author satisfaction with the process, Nature discontinued its open peer review system, and has not returned to it.

The "Disrupted" Journal of Media Practice

In 2015, the Journal of Media Practice, guest edited by the Centre for Disruptive Media and Disruptive Media Learning Lab, issued a call for submissions to a special issue titled The Disrupted Journal of Media Practice. Its stated aim was to "put forward a 
number of provocations with respect to what a 'journal of media practice' should or could be" (The Disrupted Journal of Media Practice, 2016: n.p.); these "provocations" consisted of arts and media research works-in-progress, ranging from books to podcasts to journal articles, posted to the site and subject to public commentary using the browser tool Hypothes.is. A selection of these projects would then undergo open peer review through digital marginalia for publication in the online and print Journal of Media Practice (in press). My submission to this experiment was a "living resource" for methodological approaches to practice-based research in the arts: an online text (created in $\mathrm{Scalar}^{3}$ ) that presented my own practice-based methodology, but was open for comments, revisions, and additions as other researchers added to it (Skains, 2017).

All projects published to The Disrupted Journal of Media Practice site were open to public commentary, discussion, and in-text digital annotation through the use of Hypothes.is. All commenters were asked to post marginalia comments publicly using the hashtag "\#disruptedjournal" (for all projects); the hashtag "\#practicemethods" applied mainly to my project. ${ }^{4}$ During the period of open public commentary ( 1 July to 31 December 2016), despite urgings from authors and editors to our various networks, all the projects combined garnered only 64 tagged digital annotations $(24$, or $38 \%$, of which were concentrated on one project specifically experimenting with Hypothes.is web annotation [Kalir and Dean, 2016]). My project received only two tagged items of marginalia, one of which was my own "sample" comment for readers. Of these open commenters, almost all are identifiable as fellow authors or editors of the issue (save those from Kalir and Dean's project, as noted). Likewise, once peer review began on 1 January 2017, all annotators are identifiable as reviewers. Apart from Kalir and Dean's 
project, wherein they employed contacts and classrooms to participate, these highly innovative and creative projects seem to have elicited no public response, at least via their digital marginalia.

As for the open peer review that occurred from 1 January 2017 to 31 March 2017, it was an incredibly civil affair. The digital marginalia broke down as noted in Table 1, with most of the comments (19 out of 37) focused on specific revisions to particular segments, ranging from clarification of points to inclusion of additional resources. All marginalia were created in the Hypothes.is overlay on the online version of the document, all tied to specific words, phrases, or passages. No general comments, apart from the editors' summary, were given.

Table 1. Reviewer comment types.

\begin{tabular}{|l|c|}
\hline \multicolumn{1}{|c|}{ Comment Type } & Number Received \\
\hline Positive/Neutral Interjection & 5 \\
\hline Discussion - neutral & 5 \\
\hline Editorial & 4 \\
\hline Revision - content & 19 \\
\hline Revision - structure Total & 2 \\
\hline \multicolumn{2}{c}{ 37 } \\
\hline
\end{tabular}

The official reviewers' decision was “Accepted, conditional to substantive revisions"; however, I found that the revisions required were not actually "substantive" compared to previous papers I have revised under that stamp. Given that the reviewers were able to link their annotations to specific sequences in the text, I was able to quickly identify where confusion had arisen from simple word choice, or where the addition of another citation or two would satisfy the request. The reviewers did not have to synthesize their individual annotations into "thematic" comments; as the author, I did not have to parse general comments into practical directions that I could apply to my revisions. Likewise, I could respond directly to the reviewer comments through the 
Hypothes.is interface, noting what I had changed and why, and responding to their concerns, creating a record of the review process in the digital marginalia. As a result, the revisions were quite straightforward to make, and all were accepted.

\section{Other Open Peer Review Systems}

Nature and the Journal of Media Practice are not the only academic publications that have attempted an open review and commentary system through digital marginalia. Other examples range from one-off special "experimental" issues similar to The Disrupted Journal of Media Practice, including a 2010 issue of Shakespeare Quarterly, to publications such as Wellcome Open Research who only use open reviewing models. This section offers a brief overview of these examples, and their varying degrees of success.

Richard Walker and P. Rocha da Silva discuss several of these examples in their 2015 survey of open peer review experiments. They note the relative success of Shakespeare Quarterly's 2010 special open peer review issue, particularly compared to Nature's failed trial, in that the user participation levels were much higher, and that the issue got a lot of traffic and garnered many identifiable commenters with useful reviews to the editors and authors (12). $S Q$ has not repeated the experiment, however. That $S Q$ issue was published on the MediaCommons Press platform, as was the similarly successful Planned Obsolescence book (Fitzpatrick, 2009); despite these successes, however, the platform seems to have languished, as its most recent activity dates to October 2014. Likewise, Palgrave Macmillan attempted an open peer review process for monograph proposals in 2013; it is unclear how successful this endeavor was, as it 
comprehensive to substitute for traditional peer review" (Pyne, 2014: 14).

In terms of post-publication open review, "the first journal to adopt in-channel post-publication review was Electronic Transactions in Artificial Intelligence" which published the articles, hosted community interactive discussion via digital marginalia, and then passed each paper through anonymous referees; unfortunately, the journal failed (ibid.: 7). On the other hand, Atmospheric Chemistry and Physics (ACP) utilizes a similar process, and has been successful. Authors note the rejection rate is low (20\%), but likely because the process encourages them to self-select their submissions (avoiding submitting poor papers that would be openly criticized), and reviewers receive authorship credit for their contributions (ibid., 8).

More recently, the Wellcome Trust has embraced post-publication peer-review and open access for their grant holders' research on its Wellcome Open Research (WOR) platform ${ }^{5}$ (Wellcome Trust, n.d.). The platform launched in November 2016; it has published 172 papers to date, all in a public channel that walks research papers, reviews, software and method papers, and open letters through submission, review, revision, and acceptance. Reviewers are those suggested by the author, but vetted by the editorial team to ensure they are appropriate, and are fully identified; further, their referee reports are attached to the final indexed article with assigned DOI numbers, and thus are citable contributions (Wellcome Trust, n.d.). WOR reports very good results of this new platform: in its first year, 100 of 142 submitted articles were indexed with 
Pubmed (the defined end-point of peer-approved WOR articles), taking on average 72 days from submission to indexing (Kiley, 2017). They also report that "by volume of publications indexed in PubMed, the platform is the fifth most used publication venue for Wellcome-funded researchers" (ibid., n.p.), that other institutions have begun to take up the model, and that the authors who have published through WOR have responded positively to the process (Markie, 2017).

Other well-known academic discourse sites, such as PubPeer, PubMed Commons, and F1000 Prime, engage in post-publication commentary or discourse, rather than peer-review. These sites are classifiable as online journal clubs or reviews sites, where the academic community can post a scholarly text (usually a journal article) and discuss it. PubPeer and PubMed Commons both follow a blog-type model: a discussion page is headed by the citation, and may include the article's abstract, followed by a discussion in comment form. The article itself is linked to, but not reproduced, so no marginalia is applied. F1000Prime (subscription-only) is a review and ranking site, using a method reminiscent of any consumer reviews site (e.g., GoodReads): like PLOS ONE, it utilizes a large pool of 8000 reviewers (“faculty"), who rank biomedical articles via a star system (0-3), and attach an authored, citable review. Other "faculty" may add their reviews, including "dissenting opinions" (Facultyof1000, 2014). Like PubPeer and PubMed Commons, the articles are not reproduced, and no actual marginalia is produced - only paratextual reviews and discourse.

The online journal PLOS ONE is perhaps the best-known open peer commentary publication: the ten-year-old publication works on a post-publication open peer review system (though pre-publication peer reviews are still conducted) (PLOS 
ONE, n.d.). The sheer numbers of papers and reviewers it supports on its platform (by some estimates 30,000 papers/year [Davis, 2016] and 6000+ reviewers [PLOS ONE, n.d.]) contribute to its label of "mega-journal" and its ostensible success - not to mention the $\$ 1495$ USD price tag (ibid.) to publish accepted papers. Despite the meganumbers, however, the online response rate via digital marginalia is low, as illustrated by one of its most popular articles: as of 30 July 2017, its "Most Viewed" article ${ }^{6}$, with 280,626 views, 925 shares, 160 saves, and 31 citations, had garnered only four comments (in-line annotation is not afforded on PLOS ONE). This is typical of PLOS ONE articles.

\section{Resistance to Open Discourse}

The long-documented scholarly urge to interact with texts by authoring marginalia, as well as the models and trials presented above, would seem to indicate that tools affording digital marginalia would be thoroughly embraced by the academic community. Yet these models and trials show quite clearly that open peer review and public discourse on the face of digital texts has not been a resoundingly successful venture (though the Wellcome Open Research platform perhaps demonstrates a turn in the tides - time will tell). The question remains - why not? The answer lies in the culture of academia: fears about being "scooped", about blowback, about domineering commenters, and lack of time coalesce to result in extremely poor participation in this emerging form of discourse.

Authors responding to Nature's post-trial survey indicated that they "were reluctant to take part due to fear of scooping and patent applications" (Nature Editors, 
2006: n.p.); likewise, discourse participants "might be reluctant to publicly back-up challenges to published data with unpublished data of their own for fear of being scooped, by others or by themselves" (Knoepfler, 2015: 223). This is likely more of a concern in the science, engineering, and design fields, where being first is often paramount to publication or patent grants. Articles undergoing traditional peer review are subject to the same fears, of course, but as the editors and reviewers constitute only a handful of peers rather than potentially all of them, the risk is minimal. On the other hand, the rapid publication pathway offered by open review by some publications may offset a scooping fear, given that the long delays of traditional peer review leave a much bigger window for competitors to publish first.

Bullying and fear of blowback are also significant factors. Reviewers are protected by their anonymity and often "feel emboldened to cross the line to engage in non-constructive criticism" (Knoepfler, 2015: 222), and their comments can easily be taken personally by the author(s) (Davies and Delamothe, 2005; Faulkes, 2014; Knoepfler, 2015). In traditional peer review, this anonymity is not complete, as the publication editors know who the reviewers are; awareness of their incomplete anonymity may moderate the reviewers' responses. For comments that are not anonymous, the fear of blowback can be quite limiting, particularly for more junior researchers looking for permanent positions or tenure. Disagreeing publicly with an established theory or scholar could be seen to negatively impact a researcher's career, making this group of normally quite active scholars reluctant to participate in identifiable, recorded online discourse.

On the other side of this difficulty lie commenters with no fear of blowback: 
scholars who are outside the system or already have permanent/tenured positions. These commenters may dominate the discussion, or as Davies and Delamothe put it: "the bores are threatening to take over" (2005: 1284). These "bores" can quickly turn into personal attacks and cyber-bullying, as in the case with the $B M J$ 's rapid response system (online publication of "letter-to-the-editor" type comments); the $B M J$ was forced to institute more strenuous moderation procedures as a result (ibid.). In traditional peer review, "[1]ack of interaction among reviewers prevents high prestige or forceful reviewers from dominating the review process" (Walker and Rocha da Silva, 2015: 3); in open online discussion, no such protective layer exists to de-escalate domineering or tactless participants.

Finally, time, effort, and accessibility are all barriers to participation in online academic discourse. It takes time to craft constructive and tactful comments, and F1000Prime and WOR's examples aside, these contributions are usually not citable; they offer no verifiable benefit to the contributor in either cultural capital or actual capital (Perkel, 2015). Martin Paul Eve categorizes digital marginalia (annotations, comments, reviews) as "grey literature", noting that recognition of such as "first-class scholarly objects" in academic circles may be a long time coming, simply due to their nebulous perception (2017: 6). Considering the perceived risks noted above, it is not surprising that so few researchers participate, given this lack of reward. Further, Faulkes argues that academia-specific social media have failed because successful, ubiquitous social media already exist: scholars can and do already share and discuss papers on Twitter and Facebook, so why duplicate those efforts for more restricted audiences and no benefit (2014: 260)? Given these stated fears and lack of incentives, what may be 
surprising is that any scholars take part in these initiatives at all.

\section{Promising Developments}

The history of digital marginalia in online scholarship has been a turbulent one, but that hasn't deterred developers from designing new platforms and products to encourage it. A wealth of academic social media sites (Academia.edu, ResearchGate, Diigo, FrontiersIn, Mendeley) and networking tools such as Kudos (Miah, 2017) that assist academics in networking and demonstrating their documented reach and impact to tenure boards and UK Research Excellence Framework (REF) panels shows that online networking and discourse is desirable. Academic conferences, at which discourse is the prime purpose, continue to thrive.

Tools like Genius Web Annotator and Hypothes.is afford several factors that are key to uptake for digital marginalia: ubiquity, anonymity (and conversely, identification), permanent discourse records, public and private options, in-text linking, and the ability to toggle the overlay on and off. Hypothes.is currently has an edge over similar annotation tools in terms of ubiquity, as it has formed a coalition with over 60 academic institutions and presses to make use of its services (Dwhly, 2015). This ubiquity is key: a social tool only thrives if everyone uses it (see: Facebook, Microsoft Word). As one tool becomes a standard of practice, with students incorporating it into their reading habits and academics collaborating via its interface, discourse and marginalia become commonplace, acceptable practices.

The ability to either identify oneself or remain anonymous can cut both ways: staying anonymous encourages participation, while identification encourages tactful 
participation. Further, identification coupled with permanent discourse records enable documentation of one participant's contributions, a useful element in tenure applications and impact documentation: "Hypothes.is plans improvements to its platform that include a way to validate the identities of commenters, by incorporating researchers' unique ORCID digital profiles" (Perkel, 2015: n.p.). Publications can weigh these factors in their review processes, perhaps enabling editor-authorized and moderated anonymity for reviewers who feel the need for that layer of security. Similarly, public and private options for annotations enable users to select whether their contributions will be for their eyes only, or utterances in a public discourse.

These annotation tools store their users' comments on cloud-based accounts; even if a website's content changes, the comments will remain (in Hypothes.is, these are labelled "Orphan" comments). This is useful for students and researchers who can be assured that 1) their contributions to discourse will not be lost, and 2) their notes and comments will be available to them permanently, regardless of machine upgrades or device failures. Of course, there are still technological barriers to overcome, including revisions, redesigns, and upgrades to the original content being annotated, as these actions often orphan annotations. Efforts to archive and preserve digital marginalia are of concern to librarians and digital humanities researchers, with various systems such as Eve's 2017 proposal for documentation and web archiving standards entering the discourse.

The unique abilities of these annotation tools to overlay any online content affords the user two options that few Web 2.0 interfaces do: the ability to mark up the text and comment in its "white spaces", as it were, and the ability to toggle the overlay 
off or on at will. Most Web 2.0 interfaces that permit user contributions go one of two ways: they are either entirely user-contributed (Facebook, Twitter), or user contributions are relegated to specific comment sections (blogs, online articles). The overlay feature of digital annotators brings back some of the affordances of the printed page to the digital environment, creating a virtual white space in which the reader can, if not doodle, then at least open that dialogue with the text, in the text, that it seems we as a literate species cannot resist doing. "Annotators who 'long to say something' can have the satisfaction of saying it" (Jackson, 2001: 92). Not only that, they can say it in the most useful place: anchored to the text, which is necessary as out of context annotations tend to lose meaning (Marshall and Brush, 2004: 355). Finally, the ability to toggle the overlay off means that, unlike print readers, digital readers can wipe their text clean of annotations without deleting them, removing the discomfort and distraction of having previous readers" notes "forced" upon them (Jackson, 2001: 239).

\section{Conclusion}

It is yet to be seen whether these developments will result in either a standard academic practice of making personal annotations on digital texts, or an evolution in peer review to more open discourse. If the history of institutional adoption of platforms is any indicator (see: Microsoft Word, Outlook), Hypothes.is's academic coalition may be a strong factor in its favour; likewise, the F1000 model that WOR incorporates, with reviews identified and citable with the finished paper, may encourage individual academics to participate despite their aforementioned reservations about loss of anonymity. Nonetheless, any adoption of online marginalia tools relies upon the 
attitudes of its users; thus far, scholarly fears of scooping, blowback, and bullying have vastly outweighed the benefits of engaging in these secondary oral culture forms of discourse.

Previous trials have had mixed results, with Nature's experiment in open peer review wholly underwhelming, and most others showing very limited uptake compared to the web traffic their content generates. In terms of the peer review process, most authors, including myself, found the open system useful; nonetheless, the difficulty in inspiring peers to comment openly upon scholarship in these environments poses a significant barrier to their development. WOR's model of identifying each peer review with a DOI, including them with the published paper, and linking them to the reviewer's ORCID ID has proven successful, at least amongst those participating in its system.

For these innovations to become economical enough for successful implementation, the incentives to participation need to outweigh the potential (perceived) risks. The contributions themselves would need to be permanent, identifiable, citable - i.e., published - records, assuaging fears of being scooped and enabling the contributor to build and monitor their research identity and reputation (cf. Bourke-Waite, 2015; Jackson, 2001: 91). Conversely, safeguards should be put in place that enable editors to accept anonymous (moderated) comments from researchers who fear blowback from adverse reactions to their contributions. In fact, overall moderation is necessary, as it seems to be in all corners of the Internet, to preclude issues of personal attacks and bullying behaviour.

At the moment, digital marginalia has shown itself to be something more of a gimmick than discourse. Experiments with its use in academic publications have been 
relatively unsuccessful, or unrepeated trials (or both). Yet some of these show excellent promise (WOR, SQ, F1000Prime, The Disrupted Journal of Media Practice), and the continued developments in annotation tools, publisher practices, and digital archiving indicate that digital marginalia, as the contemporary iteration of various "scholarly primitives" (Unsworth, 2000), is very likely to play a significant role in academic publishing's future.

${ }^{1}$ An excellent (fictional) example of footnote-based discourse is Mark L. Danielewski's House of Leaves (2000), which presents as a collection of documents footnoted by two different document compilers as well as the ostensible publishing editors. For more on footnotes, see (Grafton, 1999).

2 J.J. Abrams and Doug Dorst took the notion of discourse via library book annotations to an extreme interpretation, dramatizing a fictional mystery and romance in the margins of a (fictional) historical text in their novel $S$ (2013).

${ }^{3}$ A free, open source, online, multi-media publishing platform that incorporates comment and revision features, as well as native Hypothes.is integration. See "About Scalar" at http://scalar.usc.edu/scalar/.

${ }^{4}$ All comments posted on The Disrupted Journal of Media Practice site tagged with "\#disruptedjournal", can be viewed at https://hypothes.is/search?q=tag\%3Adisruptedjournal. Comments posted on my work, carrying the additional tag "practicemethods" can be viewed at https://hypothes.is/search?q=tag\%3Adisruptedjournal+tag\%3Apracticemethods. Note some comments on the latter tag apply to other projects, and not all commenters incorporated the requested tags.

${ }^{5}$ It is worth noting that the Wellcome Open Research is fully owned and controlled by Wellcome, though it does use F1000 to provide platform services (Wellcome Trust, n.d.).

${ }^{6}$ Chan WFN et al. (2012) Male Microchimerism in the Human Female Brain. PLOS ONE. Available from: http://journals.plos.org/plosone/article?id=10.1371/journal.pone.0045592 (accessed 30 July 2017). 


\section{References}

About Scalar (n.d.) The Alliance for Networking Visual Culture. Available from: http://scalar.usc.edu/scalar/ (accessed 30 July 2017).

Abrams JJ and Dorst D (2013) S. Canongate Books Ltd.

Amazon.com (n.d.) Share Notes \& Highlights. Help \& Customer Service. Available from:

https://www.amazon.com/gp/help/customer/display.html?nodeId=201242030 (accessed 29 July 2017).

Annotate.co (n.d.) Annotate.co. Available from: https://www.annotate.co/ (accessed 2 June 2016).

Blyth CS (2014) Exploring the Affordances of Digital Social Reading for L2 Literacy: The Case of eComma. In: Guikema JP and Williams L (eds), Digital Literacies in Foreign and Second Language Education, San Marcos, TX: Calico, pp. 201-226. Available from: https://calico.org/bookfiles/pdfs/DigitalLiteracies.pdf\#page $=214$ (accessed 24 November 2015).

Booth WC (1961) The Rhetoric of Fiction. Chicago: University of Chicago Press.

Bourke-Waite A (2015) Innovations in scholarly peer review at Nature Publishing Group and Palgrave Macmillan. Insights 28(2): 93-99.

Danielewski MZ (2000) House of Leaves. New York: Pantheon Books.

Davies S and Delamothe T (2005) Revitalising rapid responses. BMJ 330(7503): 1284. Available from: https://doi.org/10.1136/bmj.330.7503.1284 (accessed 2 June 2016).

Davis P (2016) PLOS ONE Shrinks by 11 Percent. The Scholarly Kitchen, 6th January. Available from: https://scholarlykitchen.sspnet.org/2016/01/06/plos-one-shrinksby-11-percent/ (accessed 30 July 2017).

Dwhly (2015) A Coalition of over 4060 Scholarly Publishers. Hypothes.is, 1st December. Available from: https://hypothes.is/blog/a-coalition-of-over-40scholarly-publishers/ (accessed 2 June 2016).

Electronic Book Review (n.d.) Policies and Submissions. Electronic Book Review. Available from: http://electronicbookreview.com/policies-and-submissions (accessed 29 July 2017).

Eve MP (2017) Towards the Digital Preservation of DOM-Node-Keyed Scholarly Web Annotations. Journal of Librarianship and Scholarly Communication, Pacific University Libraries 5(General Issue): 1-13. Available from: http://jlsc- 
pub.org/articles/abstract/10.7710/2162-3309.2178/ (accessed 20 October 2017).

Facultyof1000 (2014) 04 Key features of article recommendations. F1000Prime YouTube Channel. Available from:

https://www.youtube.com/watch?v=IbYWa31tKm8\&list=PLCEhb95PDfN6XvXbtNobEJD3tokS_GyB\&index=4 (accessed 30 July 2017).

Fajkovic M and Björneborn L (2014) Marginalia as message: affordances for reader-toreader communication. Journal of Documentation, Emerald Group Publishing Limited 70(5): 902-926. Available from: http://dx.doi.org/10.1108/JD-07-20130096 (accessed 2 June 2016).

Faulkes Z (2014) The vacuum shouts back: postpublication peer review on social media. Neuron 82(2): 258-60. Available from:

http://www.sciencedirect.com/science/article/pii/S0896627314002888 (accessed 2 June 2016).

Fitzpatrick K (2009) Planned Obsolescence | MediaCommons Press. MediaCommons Press. Available from: http://mcpress.media-commons.org/plannedobsolescence/ (accessed 2 June 2016).

Genius Web Annotator (n.d.) Genius. Available from: http://genius.com/web-annotator (accessed 2 June 2016).

Grafton A (1999) The Footnote: A Curious History. Cambridge, MA: Harvard University Press.

Hypothes.is (2015) Annotating All Knowledge. Hypothes.is, press release. Available from: https://hypothes.is/annotating-all-knowledge/ (accessed 2 June 2016).

Jackson HJ (2001) Marginalia: Readers Writing in Books. New Haven: Yale University Press.

Kalir R and Dean J (2016) Web Annotation as Conversation and Interruption. The Disrupted Journal of Media Practice. Available from:

http://journal.disruptivemedia.org.uk/web-annotation-as-conversation-andinterruption/ (accessed 30 July 2017).

Kiley R (2017) Wellcome Open Research: first year in numbers. Wellcome Open Research Blog, 16th November. Available from:

https://blog.wellcomeopenresearch.org/2017/11/16/wellcome-open-research-firstyear-in-numbers/ (accessed 28 February 2018).

Knoepfler P (2015) Reviewing post-publication peer review. Trends in genetics : TIG 31(5): 221-3. Available from:

http://www.sciencedirect.com/science/article/pii/S016895251500044X (accessed 2 June 2016). 
Macfadyen H (2011) The Reader's Devices: The Affordances of Ebook Readers. Dalhousie Journal of Interdisciplinary Management 7(Spring): 1-15. Available from: http://hdl.handle.net/10222/13823 (accessed 29 July 2017).

Markie M (2017) Wellcome Open Research author survey results. Wellcome Open Research Blog, 9th May. Available from:

https://blog.wellcomeopenresearch.org/2017/05/09/wellcome-open-researchauthor-survey-results/ (accessed 28 February 2018).

Marshall CC and Brush AJB (2004) Exploring the relationship between personal and public annotations. In: Tuscon, AZ, USA: ACM, pp. 349-357. Available from: http://portal.acm.org/citation.cfm?id=996432\&dl=GUIDE\&coll=GUIDE\&CFID $=3$ 4056623\&CFTOKEN=81038972 (accessed 3 May 2009).

MediaCommons Press (n.d.) MediaCommons Press. MediaCommons Press. Available from: http://mcpress.media-commons.org/ (accessed 29 July 2017).

Miah A (2017) The A to Z of social media for academia. Times Higher Education, 9th March. Available from: https://www.timeshighereducation.com/a-z-social-media (accessed 30 July 2017).

Nature Editors (2006) Overview: Nature's trial of open peer review. Nature. Available from: http://www.nature.com/nature/peerreview/debate/nature05535.html (accessed 2 June 2016).

O’Reilly T (2007) What Is Web 2.0: Design Patterns and Business Models for the Next Generation of Software. International Journal of Digital Economics (65): 17-37. Available from: https://mpra.ub.uni-muenchen.de/4580/ (accessed 16 June 2016).

Odell JD and Pollock CMJ (2016) Open Peer Review for Digital Humanities Projects: A Modest Proposal. ScholarWorks. Available from: https://scholarworks.iupui.edu/handle/1805/9365 (accessed 2 June 2016).

Ong W (1982) Orality and Literacy: The Technologizing of the Word. New York: Routledge.

Orgel S (2015) The Reader in the Book: A Study of Spaces and Traces. Oxford: Oxford University Press.

Palgrave Macmillan (2013) Palgrave Macmillan Open Peer Review Trial. Palgrave Macmillan. Available from: https://palgraveopenreview.wordpress.com/ (accessed 28 February 2018).

Perkel JM (2015) Annotating the scholarly web. Nature 528(7580): 153-4. Available from: http://www.nature.com/news/annotating-the-scholarly-web-1.18900 (accessed 17 April 2016). 
PLOS ONE (n.d.) Editorial and Peer Review Process. PLOS ONE. Available from: http://journals.plos.org/plosone/s/editorial-and-peer-review-process (accessed 28 February 2018a).

PLOS ONE (n.d.) Why Publish with PLOS ONE. PLOS ONE. Available from: http://journals.plos.org/plosone/static/publish (accessed 29 July 2017b).

PubMed Commons (n.d.) PubMed Commons. Available from: http://www.ncbi.nlm.nih.gov/pubmedcommons/ (accessed 2 June 2016).

PubPeer (n.d.) PubPeer. Available from: https://pubpeer.com/ (accessed 2 June 2016).

Pyne R (2014) Open Monographs and Open Peer Review at Palgrave Macmillan. Available from: https://www.stmassoc.org/2014_12_05_Beyond_Open_Access_Pyne_Monographs.pdf (accessed 14 May 2018).

ReadSocial (n.d.) ReadSocial. Available from: http://www.readsocial.net/ (accessed 2 June 2016).

Skains L (2017) Creative Practice as Research: Discourse on Methodology (Living Resource). The Disrupted Journal of Media Practice. Available from: http://scalar.usc.edu/works/creative-practice-research/.

The Disrupted Journal of Media Practice (2016) Journal of Media Practice. Available from: http://journal.disruptivemedia.org.uk/ (accessed 30 July 2017).

Unsworth J (2000) Scholarly Primitives: what methods do humanities researchers have in common, and how might our tools reflect this? In: Symposium: Humanities Computing: formal methods, experimental practice, King's College, 13 May 2000, London. Available from: http://www.people.virginia.edu/ jmu2m/Kings.500/primitives.html (accessed 20 October 2017).

Walker R and Rocha da Silva P (2015) Emerging trends in peer review-a survey. Frontiers in neuroscience 9: 1-18. Available from: http://www.pubmedcentral.nih.gov/articlerender.fcgi?artid=4444765\&tool=pmcent rez\&rendertype=abstract (accessed 2 June 2016).

Wellcome Trust (n.d.) FAQs. Wellcome Open Research. Available from: https://wellcomeopenresearch.org/faqs (accessed 28 February 2018a).

Wellcome Trust (n.d.) Referee Incentives. Wellcome Open Research. Available from: https://wellcomeopenresearch.org/for-referees/incentives (accessed 28 February 2018b).

Wellcome Trust (n.d.) The Publishing Process. Wellcome Open Research. Available from: https://wellcomeopenresearch.org/about (accessed 28 February 2018c). 
